Nova Southeastern University

Florida

\author{
Nova Southeastern University
}

NOVA SOUTHEASTERN

UNIVERSITY

NSUWorks

10-1985

\title{
Genetic Mapping of Endogenous RD-114 Retroviral Sequences of Domestic Cats
}

\author{
Roger H. Reeves \\ National Cancer Institute at Frederick \\ William G. Nash \\ National Cancer Institute at Frederick \\ Stephen J. O'Brien \\ National Cancer Institute at Frederick, sobrien1@nova.edu
}

Follow this and additional works at: https://nsuworks.nova.edu/cnso_bio_facarticles

Part of the Genetics and Genomics Commons, and the Zoology Commons

\section{NSUWorks Citation}

Reeves, Roger H.; William G. Nash; and Stephen J. O'Brien. 1985. "Genetic Mapping of Endogenous RD-114 Retroviral Sequences of Domestic Cats." Journal of Virology 56, (1): 303-306.

https://nsuworks.nova.edu/cnso_bio_facarticles/221

This Article is brought to you for free and open access by the Department of Biological Sciences at NSUWorks. It has been accepted for inclusion in Biology Faculty Articles by an authorized administrator of NSUWorks. For more information, please contact nsuworks@nova.edu. 


\title{
Genetic Mapping of Endogenous RD-114 Retroviral Sequences of Domestic Cats
}

\author{
ROGER H. REEVES, $\dagger$ WILLIAM G. NASH, AND STEPHEN J. O'BRIEN* \\ Section of Genetics, Laboratory of Viral Carcinogenesis, National Cancer Institute, Frederick, Maryland $2170 \mathrm{I}$
}

Received 16 February 1985/Accepted 11 June 1985

\begin{abstract}
The RD-114 family of endogenous retroviral sequences in domestic cats has been shown to consist of approximately 20 copies of genetically divergent virogenes per haploid genome. The chromosomal localization for four endogenous sequences (RDV1-4) was accomplished by correlating the occurrence of specific feline chromosomes with diagnostic viral DNA fragments in a panel of cat $\times$ rodent somatic cell hybrids. Analysis of the hybrid panel revealed that endogenous RD-114 sequences are dispersed on multiple cat chromosomes, that certain proviral segments are polymorphic with respect to the presence or absence of virus, and that a restriction fragment characteristic of inducible $\mathrm{RD}-114$ resides on a single feline chromosome (B3), probably at a single locus.
\end{abstract}

The RD-114 gene family in domestic cats consists of approximately 20 copies, at least 1 of which encodes an inducible, replication-competent viral genome $(1,4,5,13)$. Comparison of the restriction maps of molecularly cloned endogenous sequences $(9,12)$ indicates that they are conserved within the gag and pol regions, are bounded by long terminal repeats, and are highly divergent within the env region. This env divergence consists of both substantial deletions and substitution with an env gene that is not homologous to that of the competent RD-114 genome or to that of the progenitor of RD-114, baboon endogenous virus $(1,9)$. These truncated endogenous proviruses lack certain restriction fragments characteristic of replication-competent RD-114. Low-intensity hybridization to these characteristic fragments in Southern blots was interpreted as evidence for a low number (ca. 1 or 2 ) of inducible RD-114 proviruses in the cat genome $(9,12)$. A previous molecular analysis of several molecularly cloned endogenous RD-114 sequences (9) indicated that each viral segment studied has a unique cellular flank, which suggested that the virogenes are dispersed nonspecifically throughout the feline genome. This conclusion was in contrast to that of an early study (2), which concluded that feline RD-114 sequences are located on a single linkage group (based on a sexual backcross of $F_{1}$ hybrids to an RD-114-negative species of the leopard cat, Prionailurus bengalensis). To understand the chromosome organization of the RD-114 family and to determine if a single site for inducible RD-114 could be identified, a group of four endogenous RD-114 viral segments were chromosomally located by using a panel of rodent $\times$ cat somatic cell hybrids.

(A portion of this work was submitted by Roger H. Reeves in partial fulfillment of the requirements for the Ph.D. degree from the University of Maryland, College Park, Md.)

The genetic locations of endogenous RD-114 sequences were determined by correlating the segregation of specific DNA sequences with the presence or absence of feline chromosomes in two panels of cat $\times$ rodent somatic cell hybrids. One panel (the 17 series; see Fig. 2) was made with RAG mouse fibroblasts $\times$ fresh feline lymphocytes, and

\footnotetext{
* Corresponding author

† Present address: Developmental Genetics Laboratory, The Johns Hopkins Hospital, Baltimore, Md 21205.
}

another panel (the 49 series; see Fig. 2) was prepared with E36 Chinese hamster fibroblasts $\times$ fresh feline lymphocytes. The feline parent was a different individual in each of these panels. These hybrids preferentially retained the entire rodent genome, but segregated feline chromosomes in different combinations (6). The feline chromosome content of each hybrid was determined by examination of karyotypes with Giemsa-trypsin banding and by analysis of isozyme profiles. For a given hybrid, high-molecular-weight DNA, isozyme extracts, and karyotypes were prepared at the same cell passage. Each hybrid in the panel was analyzed karyologically (6) and electrophoretically for up to 30 isozyme markers previously mapped to feline chromosomes $(6,8)$. The segregation of individual retroviral loci was followed by hybridizing radiolabeled probes (10) synthesized from subgenomic viral fragments or unique sequences flanking endogenous proviruses to Southern blots of DNA from the somatic cell hybrids (11). In general, the multiple viral fragments were highly discordant with each other in the hybrid panel, indicating the dispersal of RD-114-specific sequences to multiple cat chromosomes (7).

A molecularly cloned probe (B1.0) representing 1.0 kilobase $(\mathrm{kb})$ of information from the gag region of replication-competent RD-114 visualized low-molecular-weight fragments of $0.7,0.9,0.95$, and $1.0 \mathrm{~kb}$ after $\mathrm{BamHI}$ digestion of cat cell DNA (Fig. 1a). Of these fragments, two (0.7 and $1.0 \mathrm{~kb}$ ) appeared as low-copy-number sequences in Bam HIdigested cat cell DNA and segregated in the somatic cell hybrid panels (Fig. 1a). The first was a $0.7-\mathrm{kb}$ fragment that corresponded to the size of an unusual gag region $\mathrm{BamHI}$ fragment from a molecularly cloned endogenous provirus analyzed previously (9). The presence of this fragment was 97\% concordant with chromosome $\mathrm{C} 2$ and highly discordant with all other cat chromosomes ( 30 to $80 \%$; see Fig. 2). These data permit the assignment of this provirus (termed $R D V 4$ for RD-114 endogenous virus 4) to feline chromosome C2.

The 1.0-kb BamHI fragment detected with the gag region probe is characteristic of replication-competent RD-114 (9) (Fig. 1a). This fragment was $100 \%$ concordant with chromosome B3 and highly discordant with all other feline chromosomes in the 49 series hybrids (Fig. 2), permitting its assignment to chromosome B3. In the 17 series, the $1.0-\mathrm{kb}$ band was discordant with chromosome B3 and with all the 

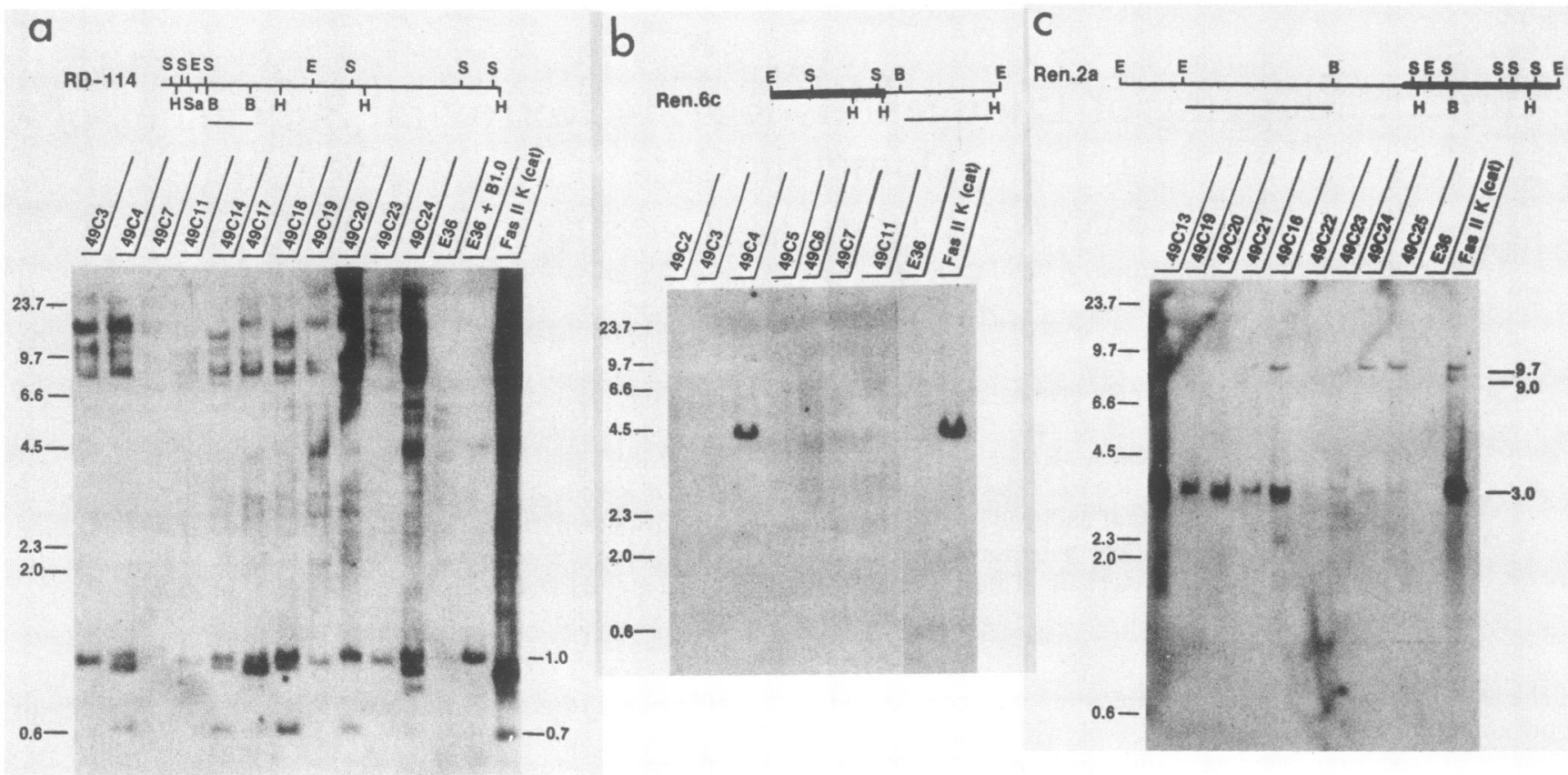

FIG. 1. Genetic mapping of endogenous RD-114 sequences. The segregation of DNA fragments recognized by RD-114-specific and flanking sequence probes was correlated with the retention or loss of cat chromosomes from cat $\times$ rodent somatic cell hybrids (Fig. 2). Restriction maps of individual RD-114 molecular clones appear above each autoradiogram and have been described elsewhere (9). Thick segments of map in $b$ and $c$ represent viral sequences and thin lines are feline cellular flanks. Probe fragments are indicated by underscored regions of the restriction maps. (a) RDVI $(1.0 \mathrm{~kb})$ and RDV4 $(0.7 \mathrm{~kb})$ resolved with a gag-specific probe from replication-competent RD-114 after BamHI digestion; fragments of $0.95 \mathrm{~kb}$ (e.g., $49 \mathrm{C} 3,49 \mathrm{C} 19$, and $49 \mathrm{C} 23)$ and $0.9 \mathrm{~kb}(49 \mathrm{C} 17,49 \mathrm{C} 18$, and $49 \mathrm{C} 24)$ were discordant with all markers in the hybrid panels; 0.7-kb fragments, weakly visualized in DNAs from $49 \mathrm{C} 3,49 \mathrm{C} 7,49 \mathrm{C} 11$, and $49 \mathrm{C} 20$ were clearly identified in longer exposures; E36 + B1.0 contains a mixture of DNA from the Chinese hamster cell line E36 and a plasmid containing a 1.0-kb gag region fragment characteristic of competent RD-114; (b) RDV2 $(3.8 \mathrm{~kb})$ resolved with a flanking sequence probe derived from endogenous RD-114 clone Ren.6c after HindIII digestion of hybrid DNA; (c) RDV3 (alleles of 9.0 and $9.7 \mathrm{~kb}$ ) resolved with a flanking sequence probe from clone Ren.2a; a 3.0-kb sequence was also visualized by this probe. Fas $11 \mathrm{~K}$ is a domestic cat heterozygous for the restriction fragment-length polymorphism.

remaining cat chromosomes. The lowest discordance value was feline chromosome $A 3(D=13 \%)$, which raised the possibility of an additional RDV locus on feline A3, but this chromosome was highly discordant $(D=33 \%)$ with the 1.0-kb fragment in the 49 series (Fig. 2). The perfect concordance of the $1.0-\mathrm{kb}$ fragment with chromosome B3 in the 49 series, but not in the 17 series, is consistent with the conclusion that the feline parent of the 17 series was heterozygous for an endogenous virus on B3 and the same locus was homozygous positive in the feline parent of the 49 series. This interpretation is supported by the observation that all the 17 series discordant hybrids were of the "fragment negative/chromosome positive" variety. Because of the inference that the segment on chromosome B3 represents the inducible locus in cats, it has been named RDVI.

Two endogenous sequences were mapped by using unique DNA sequences flanking proviruses as probes. These probes were derived from molecular clones of endogenous RD-114 sequences isolated from a genomic library of cat kidney DNA (9). The first flanking sequence probe, Fl.6c, was derived by a HindIII/BamHI double digest of clone Ren.6c (Fig. 1b). This probe detected a HindIII restriction fragmentlength polymorphism when hybridized to cellular DNA of domestic cats. When examined with this clone, three types of cats were found, as follows: (i) homozygotes for a $3.5-\mathrm{kb}$ fragment; (ii) homozygotes for a 3.8-kb fragment; and (iii) heterozygotes for these two allelic forms. The parent of the 17 series was heterozygous, while the 49 series parent was homozygous for the $3.5-\mathrm{kb}$ fragment. Neither mouse nor hamster DNA contained a homologous segment (Fig. 1b). This 3.5/3.8-kb polymorphic HindIII fragment identified an endogenous sequence locus, designated $R D V 2$, which was concordant $(97 \%)$ with feline chromosome A1 and highly discordant with all of the other feline chromosomes. One of the hybrids, $49 \mathrm{C} 22 \mathrm{D} * \mathrm{E}$, contained only the long arm of chromosome A1(q). Since this hybrid was positive for both $R D V 2$ and the esterase-D isozyme marker (ESD), both $R D V 2$ and $E S D$ can be regionally assigned to chromosome Alq.

Two cellular flanking sequence probes were readily isolated from clone Ren.2a (Fig. 1c). A 1.6-kb EcoRI flanking DNA fragment from the left end of this clone hybridized to multiple fragments in cat cellular DNA, indicating that a reiterated sequence was present in this region. The adjacent 3.6-kb BamHI/EcoRI fragment (probe Fl.2a) consistently recognized fragments of 9.7 and $3.0 \mathrm{~kb}$ in EcoRI-digested cat cellular DNA (Fig. 1c). The 3.0-kb fragment was present in every hybrid that contained any cat chromosomes, suggesting that it may be a member of a widely dispersed family of repetitive sequences. The $9.7-\mathrm{kb}$ fragment and a $9.0-\mathrm{kb}$ restriction fragment-length polymorphism detected by the same probe were highly concordant with feline chromosome B3 and discordant with all other feline chromosomes, indicating that the endogenous sequence in clone Ren.2a (designated $R D V 3$ ) maps to chromosome B3 (Fig. 2).

Genetic mapping with sexual genetics is difficult for a 
Feline Chramosane

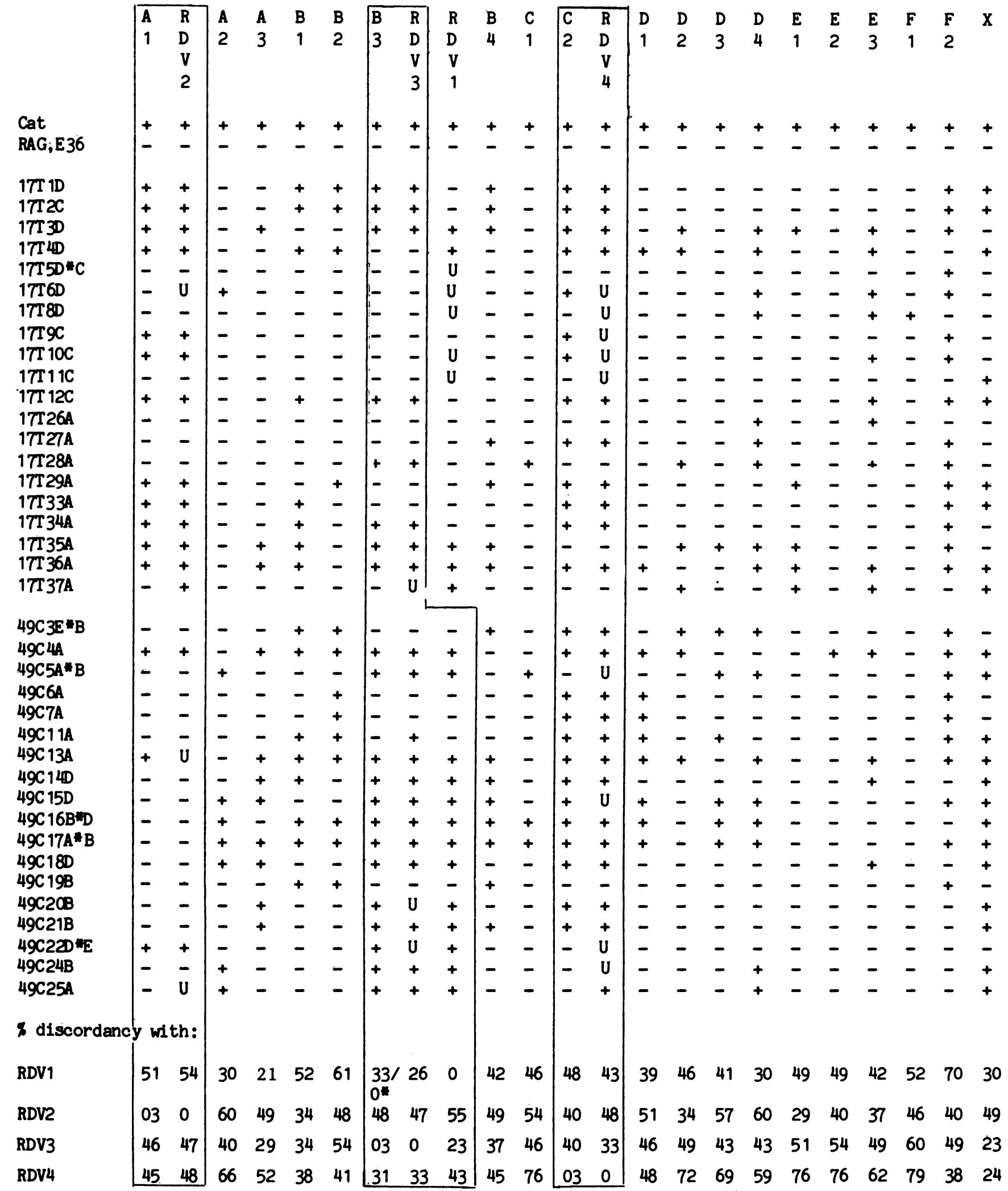

FIG. 2. Chromosome and RD-114 phenotype of cat $\times$ rodent somatic cell hybrids. Percent discordance between each chromosome and markers of four endogenous RD-114 loci is indicated. RDVI showed 33\% discordance with chromosome B3 in the 17 series hybrids and $0 \%$ in the 49 series hybrids $\left({ }^{*}\right)$. U, Not determined. Hybrids were scored for Giemsa-trypsin karyology and specific isozyme markers previously mapped to feline chromosomes $(3,6,7)$. 
multigene family such as this one, in which the complexity and low levels of variation between individuals do not provide assayable markers for the segregation of the genes in question. Analysis of complex gene families is simplified, however, in somatic cell hybrids that segregate chromosomes of the species of interest. Through the use of detailed restriction maps and unique sequence probes derived from molecular clones of endogenous sequences, individual RD-114 loci have been identified and mapped to specific feline chromosomes. Several of our findings suggest that the replication-competent $\mathrm{RD}-114$ genome resides at a single locus. First, a gag region fragment characteristic of the genome of the inducible virus has not been seen in numerous molecular clones of defective RD-114 proviruses. This fragment hybridizes with low intensity in genomic blots, indicating that it is present at low copy number in the cat genome (9). A second fragment characteristic of the pol-env region of the competent virus has also been reported to be present as a single copy sequence (12). Second, the characteristic fragment residues on a single chromosome, B3. Finally, some homologs of chromosome B3 present in the cat population do not exhibit this fragment, an unlikely situation if several copies of the viral genome are present on each homolog.

Roger H. Reeves is a fellow of the Damon Runyon-Walter Winchell Cancer Fund (DRG 835).

\section{LITERATURE CITED}

1. Benveniste, R. E., and G. J. Todaro. 1974. Evolution of C-type viral genes: inheritance of exogenously acquired viral genes. Nature (London) 252:456-459.

2. Benveniste, R. E., and G. J. Todaro. 1975. Segregation of RD114 and FeLV related sequences in crosses between domestic cat and leopard cat. Nature (London) 257:506-508.
3. Bobro, M., and J. Cross. 1971. Differential staining of human and mouse chromosomes in interspecific cell hybrids. Nature (London) 251:77-79.

4. Fischinger, P. J., P. T. Peebles, S. Nomura, and D. K. Haapala. 1973. Isolation of an RD-114-like oncornavirus from a cat cell line. J. Virol. 11:978-985.

5. Livingston, D. M., and G. J. Todaro. 1973. Endogenous type C virus from a cat cell clone with properties distinct from previously described feline type $C$ virus. Virology 53:142-151.

6. O'Brien, S. J., and W. G. Nash. 1982. Genetic mapping in mammals: chromosome map of domestic cat. Science 216:257-265.

7. O'Brien, S. J., W. G. Nash, C. A. Winkler, and R. H. Reeves. 1982. Genetic analysis in the domestic cat as an animal model for inborn errors, cancer and evolution, p. 67-90. In G. Migaki, R. J. Desnick, and D. F. Patterson, (ed.), Animal models of inborn errors of metabolism. Alan R. Liss, New York.

8. O'Brien, S. J., J. M. Simonson, and M. A. Eichelberger. 1982. Genetic analysis of hybrid cells using isozyme markers as monitors of chromosome segregation, p. 342-370. In J. W. Shay (ed.), Techniques in somatic cell genetics. Plenum Publishing Corp., New York.

9. Reeves, R. H., and S. J. O'Brien. 1984. Molecular genetic characterization of the RD-114 gene family of endogenous feline retroviral sequences. J. Virol. 52:164-171.

10. Rigby, P. J. W., M. Dieckmann, C. Rhodes, and P. Berg. 1977. Labeling deoxyribonucleic acid to high specific activity in vitro by nick translation with DNA polymerase I. J. Mol. Biol. 113:237-251.

11. Southern, E. M. 1975. Detection of specific sequences among DNA fragments separated by gel electrophoresis. J. Mol. Biol. 98:503-517.

12. Spodick, D. A., L. H. Soe, and P. Roy-Burman. 1984. Genetic analysis of the feline RD-114 retrovirus-related endogenous elements. Virus Res. 1:543-555.

13. Todaro, G. J., R. E. Benveniste, M. M. Lieber, and D. M. Livingston. 1973. Infectious type C viruses released by normal cat embryo cells. Virology 55:506-515. 